that their supposed affinities appear. In fact, apart from the numerals the resemblances are very slight and it may be possible that they indicate contact rather than relationship. Further study of these Indians is greatly needed. Their reference to the Paiute stock in the present paper is only provisional.

Contrasting the distribution of the Yokut tribes collectively with that of the five undoubted Paiute tribes of the same region, it appears that the Yokut inhabit the hot San Joaquin Valley (Lower Sonoran) and adjacent foothills (Upper Sonoran), while the Paiute tribes inhabit the cooler Ponderosa pine belt of the mountains (Transition zone). Excepting the Chukchancys, who have pushed a little way into the Ponderosa pines, none of the Yokut tribes reach higher than the Digger pine belt, and only three of them (Chuk-chan'-cy, Koshsho'-o and Cho-ki'-min-ah) reach high enough to come within this belt.

It would be convenient to speak of the linguistic families or stocks as 'nations'as the Paiute nation, the Yokut nation, and so on-but such a designation would be incorrect, for the reason that nothing like political unity of the component tribes exists.

As well known to ethnologists, the names of linguistic stocks often present difficulties, and the names of tribes still greater difficulties. In cases where Indians have a stock name for themselves-as the desert Paiute and Shoshone; or a tribal nameas Wuksache, Wiktchumne, Chukchancythere is no trouble, but in cases where they have no tribal name, and such cases are common, various complications arise.

Many tribes speak of themselves as THE PEOPLE, and in numerous instances their word for people has been adopted by ethnologists (and sometimes by themselves) in lieu of a tribal or stock name. Among the family names of this class are Midu,
Muwa and Yokut; among the tribal names are Nim and New- $00^{\prime}-\mathrm{ah}$, both meaning people-the first from neum or, nüm, the last from new'-ah. In some cases a locative or place name is prefixed to the stock name to distinguish the tribe-as Ahwanee Muwa, Chowchilla Muwa, and so on. In the case of tribes having no definite name for themselves it is sometimes practicable to use the name given them by another tribe-for every tribe is sure to have a name in the language of its neighbor. Such names are often based on points of the compass, meaning north people, south people, and so on.

While the Yokuts have no common or stock name for themselves (Yokut being the word meaning 'people' in some, but not all, of the tribes), every tribe has a fixed and definite tribal name. In the case of the desert Paiutes the opposite condition prevails, for all the tribes use the stock name, while only a few have definite tribal names. Similarly, several of the- Paiute tribes on the west slope of the Sierra appear to lack distinctive names for themselves; hence the names here given for them are provisional and tentative. The doubtful names are Nim, Holkoma, Pakanepul, and possibly also New-oo'-ah; the well-established names are Kokoheba, Emtimbitch, Wuksache. Of these, Kokoheba is a place name-the name of a village-which has come to be applied to the tribe.

\section{Hart Merriam.}

\section{SCIENTIFIC BOOKS.}

THE CRYPTOGAMIC BOTANY OF THE HARRIMAN EXPEDITION.*

THE scientific results of the Harriman expedition to Alaska are beginning to be made public and the handsomely bound volume recently issued gives us the first of the three

* 'Harriman Alaska Expedition,' Volume V., 'Cryptogamic Botany.' New York, Doubleday, Page and Co. 1904. Pp. 404 and 44 plates. 
botanical volumes promised, and includes the results of exploration in the field of the lowest plants. How little was hitherto known of some of the lower plants of this region is forcefully illustrated among the fungi, in which group only fifteen species had been definitely reported from Alaska prior to this publication. That there was no professional mycologist present with the expedition will account for the fact that only 252 species of fungi were collected by the members of the expedition or are reported for the first time in this volume. With conditions as favorable as those indicated in the introduction, the number collected might readily have been quadrupled, for a thousand species of fungi would be only an average collection to be picked up in almost any favorable locality, by a professional mycologist. Most of the species that were collected were due to the sharp eyes of Professor Trelease, who collected also most of the lichens, mosses and hepatics that were secured by the expedition. It is wholly reasonable to suppose that the results of the present expedition represent only from one eighth to one tenth of the entire fungus flora of Alaska when fully known, for we must realize that Alaska with its islands and peninsulas, if spread on the map of the rest of the United States with its upper corner at St. Paul, Minnesota, would extend from Savannah, Georgia, very nearly to Santa Barbara, California, and cover eight states and parts of a dozen more.

Among the fungi the new species are not excessive, amounting to thirty-eight, of which twenty-eight are by Saccardo or Saccardo and Scalia, five are by Trelease, one by Bresadola and four by Peck. By far the largest number are from the ascosporous series (including the Fungi imperfecti). The forty species of rusts form a smaller ratio to the whole than would naturally be expected. - A useful hostindex concludes the story of the fungi.

The 'Lichens of Alaska,' by Professor Clara E. Cummings, of Wellesley, occupies 82 pages, and includes a review of the work of previous collections from the region, so that the total of 462 species from Alaska doubtless represents more than half of the actual lichen flora of the region that complete exploration will ultimately make known. A most valuable addition to this part of the work is the series of keys to the species in each of the genera which clearly demonstrates the belief we have always held that, however much the early writers on American lichens struggled with a stilted and pedantic language to bury from view the easily discernible characters of the plants they described, lichens really possessed characters that could be easily tabulated when they were approached in a really rational way. The success with which the author has accomplished this is greatly to her credit and adds a most valuable feature to this portion of the book.

The part on the 'Algæ,' by Professor Saunders has already been published in advance of its appearance here, and is reprinted in the volume at hand with a careful preservation of the original pagination, so that citation from the original publication can be made from the present work with ease and accuracy. In the presence of so many lamentable failures on the part of editors to make this course possible, this feature is worthy of the highest commendation. The list contains 380 species of algæ, nearly two thirds of which were new to Alaska at the time of publication.

The 'Mosses of Alaska' also represents a reprint originally published in 1902 by Cardot and Theriot; 280 species are included. The hepatics by Professor Evans is also a reprint; the Harriman expedition nearly doubled the list in this group, the number of species now known from Alaska reaching 80 .

The final portion of the work is by Professor Trelease and includes the ferns and fern allies. Seventy-four species are included in the list, which represents a large series when one considers so large an area belonging to a subarctic region, and yet when we consider that the central Californian 'golden-back' fern (Ceropteris. triangularis) is found as far north as Cape Nome we are forced to the conclusion that there are climatic conditions existing in the Alaskan region that are favorable to the growth of plants of a much lower latitude as. compared with other boreal parts of the earth. The plant figured as Botrychium lunaria incisum as 'new to Alaska' is quite typical' 
$B$. boreale, of which several collections have now been made from Alaska.

While the work as a whole would impress the average non-botanical reader as a list of plants merely, only those who have been engaged in distributional studies will understand the immense amount of careful and critical labor involved in the study of the material that underlies its preparation. It may be too early to form any general conclusions regarding the relations of the Alaskan flora, and it may be that the editors are expecting to include this in a later account in the two forthcoming volumes on the Spermatophytes which are expected ' in the early part of 1904,' but we are disappointed only in the absence of some more general discussion of the relations of the Alaskan flora to other regions.

The mechanical execution of the work is a great credit alike to the projector of the expedition, to the editors, and to the publishers. The heliotype plates are especially fine.

\section{LUCIEN M. UNDERWOOD.}

Columbia University, May 19, 1904.

The Eye, its Refraction and Diseases. By Edward E. Gibbons, M.D. $19 \times 23 \mathrm{~cm}$., pp. ix +472 , index. New York, The Macmillan Company; London, Macmillan \& Co., Ltd. 1904.

The English-speaking student of ophthalmology whose special desire is to cultivate that subject as a useful art, has been much in need of a manual which should concern itself especially with the science of optics, geometrical and physiological, as applied in practise, such application being nowadays an important part of the daily routine work of the oculist.

A few years ago the elegant little 'Handbook' of Suter appeared, giving what was necessary in a geometrical line, and a short time after that Tcherning's 'Physiological Optics' was translated. Much of the subject matter of these two books necessarily enters into this volume of Dr. Gibbons, but much else has been included, sometimes in a cursory way, yet one finds here an excellent manual for the student or physician who thinks
Landolt a little stiff for the first bout, and wishes the encouragement of the colloquial and sympathetic. If one expects in this volume any consideration of, or allusion to, the inflammatory affections with which text-books on 'Diseases of the Eye' are often almost exclusively concerned, he will be disappointed. Only by a liberal construction of the word disease to include refraction anomalies and muscular insufficiencies can the contents of the book be made to justify the title page. The author need not be censured for thus limiting his subject matter. Conditions of the art and of the market make it desirable that just this ground should be covered in very much this way. But the title of the book is misleading.

The first seventy-five pages are taken up with geometrical optics. In order to appreciate this part, one must know that the audience addressed is entirely made up of medical men, and that the subject matter of the address is purely mathematical. Young men who have ability and predilection for mathematics rarely choose medicine as a profession, and most physicians shy at any kind of a formula that can not be put up by a druggist. Yet a man who wishes to be an oculist finds, after six or eight years devoted to a science not particularly formal, that he is face to face with a well-developed mathematical specialty, and he is lucky if he remembers enough of his undergraduate work to help him through. An occasional one will regard this situation as refreshing-he will write the book. More will accept it with resignation, and ask for what they miscall a 'practical' knowledge of the subject, obtained by means of diagrams and illustrative cases with very little of the condensation and generalization attractive to the former. It is the delicate task of the author to give the reader all he needs of the one, and a little more than he thinks he needs of the other. The indispensable in this case is just so much of the theory of centered optical systems as will enable one to combine the three principal refracting surfaces of the eye with two others belonging to any spectacle lens that the patient may wish to wear, and to calculate the place of the cardinal points, 
and the size of the images. The 'Dioptrische Untersuchungen' 'in words of one syllable' is hardly attainable, but that of it which is indispensable seems here to have been presented in the simplest possible manner. Systems are compounded and equivalent lenses calculated by the aid of Newton's formula, ' $c c^{\prime}=f f^{\prime}$ ', in which the principal foci of a system are used as coordinates from which conjugate foci are measured by a symmetrical notation. In this way a good working theory is obtained, and is so illustrated by examples chosen from the eye itself, that the student becomes familiar with the constants with which he will be subsequently concerned. Chapter V., the following, is on 'visual acuity.' From this on the science is not very much separated from the useful art by which it is likely to be applied in practise. Most of the subject matter which comes to us by or through Tcherning and Landolt appears here and is in general very well presented. The author does not hesitate to express an opinion of his own occasionally. Among other things he says the Morton ophthalmoscope is the best for refraction purposes, from which we judge the hole in the small mirror is made larger than it was in the earlier instruments. The horopter has been robbed of half its interest. This devilish contraption which kept Helmholtz awake nights and which lesser men have dodged as 'un problème de mathématiques assez compliqué et sans grand intérêt' floats in from somewhere this side of the Rocky Mountains bearing a brand new name and shrunk to nothing more or less than a toric surface. We prefer it with its old euphonious title and complicated contour.

Near two hundred pages of the book are taken up with normal and abnormal refraction. Included in this part is a chapter on optometers of some historic and theoretic interest; also a chapter on retinoscopy well presented. Retinoscopy is a sine qua non to a few men who paralyze all cases and do a roughand-ready refraction practise among infirmary patients. But retinoscopy is also a necessary part of the modern oculist's equipment and deserves the space here given to it.

Dr. Gibbons in common with most other oculists thinks there is no place in the world for the 'refracting optician.' $\mathrm{He}$ does not devote much attention to his natural enemy, but he offers him no quarter. From a purely medical standpoint the oculist may have the best of the argument, but the refracting optician is abroad in the land and is not likely to be preached out of existence. There are economic conditions which contribute to his success and justify his claim to recognition.

It is of course quite proper that the author should give a list of cycloplegics and their peculiarities and the method of procedure to be adopted by those who habitually use them in the fitting of glasses. The number of such is so great that they can not be ignored, but why so many oculists still think it worth while to acquire the useless and irrelevant information that comes from fitting glasses to a paralyzed eye is hard to tell. It may be gathered from the text that the author thinks such a course should be the rule rather than the exception.

In the line of petty fault finding it might be said that Holmgren's color test is rather meagerly given, that the description of a Rochon prism is made to do duty for a Wollaston, that it is a little dogmatic to assert in an unqualified way that lens and vitreous opacities are caused by eye-strain. The algebra has suffered in one or two places from clerical errors, and the table at the top of page 386 seems to have been obtained empirically under conditions which, if well understood, have certainly not been accurately described.

The letter press is as good as could be desired. The illustrations that have been made for the book are excellent. Their number is greatly increased by those borrowed from the instrument-maker, whose courtesy serves a double purpose. On the whole the author, publisher and instrument-maker should be well satisfied with the accomplishment.

New York City.

William S. Dennett.

\section{SCIENTIFIC JOURNALS AND ARTICLES.}

The May number of the Botanical Gazette contains the following papers: Ethel Sargant has written concerning 'The Evolution of the 